\title{
Pediatric reference values for arterial stiffness parameters cardio-ankle vascular index and CAVIO
}

Citation for published version (APA):

Jurko, T., Mestanik, M., Jurko, A., Spronck, B., Avolio, A., Mestanikova, A., Sekaninova, N., \& Tonhajzerova, I. (2018). Pediatric reference values for arterial stiffness parameters cardio-ankle vascular index and CAVIO. Journal of the American Society of Hypertension, 12(11), e35-e43. https://doi.org/10.1016/j.jash.2018.10.003

Document status and date:

Published: 01/11/2018

DOI:

10.1016/j.jash.2018.10.003

Document Version:

Accepted author manuscript (Peer reviewed / editorial board version)

\section{Please check the document version of this publication:}

- A submitted manuscript is the version of the article upon submission and before peer-review. There can be important differences between the submitted version and the official published version of record.

People interested in the research are advised to contact the author for the final version of the publication, or visit the DOI to the publisher's website.

- The final author version and the galley proof are versions of the publication after peer review.

- The final published version features the final layout of the paper including the volume, issue and page numbers.

Link to publication

\footnotetext{
General rights rights.

- You may freely distribute the URL identifying the publication in the public portal. please follow below link for the End User Agreement:

www.umlib.nl/taverne-license

Take down policy

If you believe that this document breaches copyright please contact us at:

repository@maastrichtuniversity.nl

providing details and we will investigate your claim.
}

Copyright and moral rights for the publications made accessible in the public portal are retained by the authors and/or other copyright owners and it is a condition of accessing publications that users recognise and abide by the legal requirements associated with these

- Users may download and print one copy of any publication from the public portal for the purpose of private study or research.

- You may not further distribute the material or use it for any profit-making activity or commercial gain

If the publication is distributed under the terms of Article $25 \mathrm{fa}$ of the Dutch Copyright Act, indicated by the "Taverne" license above, 


\section{PEDIATRIC REFERENCE VALUES FOR ARTERIAL STIFFNESS \\ PARAMETERS CARDIO-ANKLE VASCULAR INDEX (CAVI) AND CAVI}

Tomas JURKO ${ }^{\mathrm{a}}$, Michal MESTANIK ${ }^{\mathrm{b}, \mathrm{c}^{*}}$, Alexander JURKO Jr ${ }^{\mathrm{d}}$, Bart SPRONCK ${ }^{\mathrm{e}, \mathrm{f}}$, Alberto AVOLIO ${ }^{\mathrm{e}}$, Andrea MESTANIKOVA ${ }^{\mathrm{b}, \mathrm{c}}$, Nikola SEKANINOVA ${ }^{\mathrm{c}, \mathrm{b}}$, Ingrid TONHAJZEROVA ${ }^{\mathrm{c}, \mathrm{b}}$

a Clinic of Neonatology, Comenius University in Bratislava, Jessenius Faculty of Medicine in Martin (JFM CU), University Hospital Martin, Kollarova 2, Martin, 03601, Slovak Republic.

b Biomedical Center Martin JFM CU, Mala Hora 4D, Martin, 03601, Slovak Republic.

c Department of Physiology JFM CU, Mala Hora 4C, Martin, 03601, Slovak Republic.

d Pediatric Cardiology, Kollarova 13, Martin, 03601, Slovak Republic.

e Department of Biomedical Sciences, Faculty of Medicine and Health Sciences, Macquarie University, 75 Talavera Road Sydney, NSW 2109, Australia

f Department of Biomedical Engineering, School of Engineering \& Applied

Science, Yale University, 10 Hillhouse Avenue, New Haven, CT 06520-8267, United States.

Conflicts of interest: None declared.

Funding: Slovak Scientific Grant Agency under grant VEGA 1/0044/18, Slovak Research and Development Agency under grant APVV-15-0075, and the project implementation „Biomedical Center Martin“ ITMS code: 26220220187, supported by the Operational Programme Research and Innovation funded by the ERDF. 


\section{*Corresponding author:}

Michal Mestanik, M.D., Ph.D.

Biomedical Center Martin, Jessenius Faculty of Medicine in Martin, Comenius

University in Bratislava, Mala Hora 4D, 03601 Martin, Slovak Republic

E-mail: mestanik@jfmed.uniba.sk,mestanik@gmail.com

Phone: 00421432633466

E-mail addresses of the authors:

Tomas Jurko: jurkotom@gmail.com

Alexander Jurko Jr: 1tvsro@gmail.com

Bart Spronck: bart.spronck@yale.edu

Alberto Avolio: alberto.avolio@mq.edu.au

Andrea Mestanikova: andrea.mestanikova@gmail.com

Nikola Sekaninova: nikola.sekaninova@gmail.com

Ingrid Tonhajzerova: tonhajzerova@jfmed.uniba.sk 


\begin{abstract}
The process of arteriosclerosis begins early in life and cardiovascular risk factors identified in childhood tend to persist into adulthood. Cardio-ankle vascular index (CAVI), a recent parameter of arterial stiffness, is considered an independent predictor of cardiovascular risk. However, there are no studies reporting sex- and age-specific physiological values of CAVI in childhood. We aimed to establish reference values for CAVI and its blood pressure-corrected variant $\left(\mathrm{CAVI}_{0}\right)$ in 500 healthy children and adolescents aged 7 to 19 years and to study potential relationships with anthropometric indices.
\end{abstract}

Sex- and age-specific distributions of CAVI and CAVIo values in healthy children and adolescents are presented. Boys aged 15-19 years had lower CAVI than girls, which could result from CAVI's slight blood pressure dependence. CAVI $\mathrm{C}_{0}$ did not show such sex difference. Body roundness index — a novel parameter to quantify abdominal fat was a strong anthropometric predictor of both CAVI and CAVI0.

This is the first study providing pediatric age- and sex-specific reference values for arterial stiffness parameters CAVI and CAVI 0 . The presented data can contribute to the understanding of the evolution of these indices during childhood and adolescence. Under specific conditions, CAVIo may offer more robust information about arterial stiffness than standard CAVI.

Keywords: vascular stiffness, arteriosclerosis, reference values, pediatrics, blood pressure, anthropometrics 


\section{INTRODUCTION}

It is well known that the process of arteriosclerosis, sometimes in combination with atherosclerosis, begins early in life. Furthermore, the presence of risk factors identified in childhood, e.g., overweight or hypertension, tends to be stable and persist into adulthood (Falkner 2008; Juhola et al. 2011). Cardiovascular diseases present a large burden on the adult population. Despite some improvements in mortality rates, cardiovascular morbidity shows an increasing trend and causes more premature deaths than any other condition (Nichols et al. 2014). Early evaluation of arterial structure and function during childhood could help to identify those individuals with increased risk of later cardiovascular events within the initial, potentially reversible, phase of vascular damage (Fernhall and Agiovlasitis 2008; Ghazi et al. 2017).

Arterial stiffness reflects alterations of both structural and functional properties of the arterial tree and is considered to be an independent predictor of cardiovascular risk (Laurent et al. 2006; Townsend et al. 2015). However, conventional markers of arterial stiffness, e.g., pulse wave velocity (PWV), are substantially affected by acute changes in blood pressure (BP) during examination which can lead to erroneous conclusions (Spronck et al. 2015). To overcome this problem of BP dependence, Shirai et al. proposed cardio-ankle vascular index (CAVI) (Shirai et al. 2006a). CAVI combines stiffness index $\beta$ and the Bramwell-Hill equation to obtain an index that can be calculated using arterial BP and PWV (as opposed to $\beta$ which is calculated from arterial BP and diameter). Recently, CAVI was found to theoretically be still partially affected by BP during the time of measurement, albeit to a lesser degree than PWV (Spronck, Avolio, et al. 2017). Furthermore, a novel BP-corrected index - $\mathrm{CAVI}_{0}-$ was 
proposed, which is suggested to offer a less BP-dependent index of arterial stiffness (Mestanik et al. 2017; Spronck, Avolio, et al. 2017; Spronck, Mestanik, et al. 2017).

In adults, CAVI increases progressively with age and with risk factors such as hypertension, diabetes mellitus, or smoking (Shirai et al. 2011; Wang et al. 2013; Wohlfahrt et al. 2017). Moreover, this increase is associated with distinct morphological and functional measures of arteriosclerosis, e.g., carotid intima-media thickness, carotid distensibility, coronary artery stenosis, and arterial calcification (Okura et al. 2007; Park et al. 2012). In children, there are only few studies on arterial stiffness measured using CAVI. These studies showed increased CAVI in adolescents with essential hypertension compared to healthy controls, positive correlation with age, and an inverse relationship with body mass index (BMI) and sleep duration (Mestanik et al. 2016, 2017; Morita et al. 2016; Philip et al. 2015). However, the interpretation and clinical application of CAVI as a marker of arterial stiffness in pediatric healthcare is limited due to absence of studies on its sex- and age-specific physiological values during childhood. Therefore, we aimed to 1) collect reference values for CAVI and CAVI in 500 healthy children and adolescents aged 7-19 years, and to 2) study potential relationships of CAVI and CAVIo with conventional and novel anthropometric indices considered as predictors of cardiovascular risk. 


\section{METHODS}

The study was approved by the Ethics Committee of Jessenius Faculty of Medicine in Martin, Comenius University in Bratislava in accordance with the 1964 Helsinki declaration and its later amendments. All participants and their parents/legal representatives were carefully instructed about the study protocol and they gave written informed consent to participate in the study prior to examination.

\section{Subjects}

The study population consisted of 500 healthy children and adolescents (250 males) aged 7-19 years recruited from local schools and clinical offices. The following exclusion criteria were strictly applied prior to enrolment: smoking, history of recent acute illness or chronic cardiovascular, respiratory, endocrine, neurological, metabolic, or infectious diseases or mental disorders, obesity, and medication or dietary supplementation which could affect the cardiovascular or autonomic nervous systems.

\section{Anthropometric measures}

Height $(h, \mathrm{~m})$ and weight $(w, \mathrm{~kg})$ were measured, and body mass index (BMI, $\left.\mathrm{kg} / \mathrm{m}^{2}\right)$ was calculated as $\mathrm{BMI}=w / h^{2}$. The corresponding adult BMI was assessed for each participant aged $<18$ years as the BMI value potentially reached at age 18 years if the subject's BMI would remain at the same percentile level according to the Extended International Obesity Task Force reference values (Cole and Lobstein 2012). Waist 
circumference (WC, m) was measured at the midpoint between the lowest border of the rib cage and the upper border of the iliac crest at the end of normal expiration. Body surface area $\left(\mathrm{BSA}, \mathrm{m}^{2}\right)$ was estimated using the Mosteller equation as: $\mathrm{BSA}=$ $\sqrt{h \times w / 36}$, where $h$ is height (m) and $w$ is weight $(\mathrm{kg})$ (Mosteller 1987).

In addition to conventional anthropometric parameters, two recently proposed indices were evaluated: a body shape index (ABSI) and body roundness index (BRI), which combine information about waist circumference, height, and BMI (only ABSI) to estimate the amount of abdominal fat tissue (Krakauer and Krakauer 2012; Thomas et al. 2013). ABSI and BRI were calculated using formulas:

$$
\begin{aligned}
& \mathrm{ABSI}=\frac{\mathrm{WC}}{\mathrm{BMI}^{2 / 3} \times h^{1 / 2}} \text {, and } \\
& \mathrm{BRI}=364.2-365.5 \times \sqrt{1-\left(\frac{\mathrm{WC} /(2 \pi))^{2}}{(0.5 \times h)^{2}}\right)} .
\end{aligned}
$$

\section{Protocol}

Examinations were carried out under standard conditions according to recommendations (Laurent et al. 2006) (room temperature $22{ }^{\circ} \mathrm{C}$, minimization of stimuli) between 8.00 and 10.00 a.m. Participants were instructed to avoid physical exercise and consumption of substances that could affect cardiovascular function (e.g., caffeine, alcohol) 24 hours prior to the examination. Before the examination, participants were resting in supine position for 15 minutes to avoid potential effects of stress. 
The assessment of arterial stiffness indexed by CAVI, parameters for calculation of $\mathrm{CAVI}_{0}$, and other cardiovascular parameters was performed using the vascular screening system VaSera 1500N (Fukuda Denshi Co., Tokyo, Japan). At the time of examination, subjects remained in supine position with both arms on the bed, parallel to the body, and with limb cushions placed below the elbows and heels to prevent contact of the limb cuffs with the bed. Electrocardiographic electrodes were placed on both wrists, oscillometric blood pressure (BP) cuffs wrapped around the arms and ankles, and a microphone for phonocardiography placed on the sternum at the level of the second intercostal space.

\section{Evaluated parameters}

CAVI and CAVI 0 were determined from simultaneous electrocardiographic, cardiac phonographic, brachial and ankle pulse wave recordings and subsequent brachial and ankle BP measurements.

\section{Cardio-ankle vascular index calculation}

CAVI-values for the left and the right side were directly calculated by the VaSera device using the following equation:

$$
\mathrm{CAVI}=a \times\left[(2 \rho / \Delta P) \times \ln (\mathrm{SBP} / \mathrm{DBP}) \times \mathrm{PWV}^{2}\right]+b
$$

with SBP and DBP the right brachial systolic and diastolic blood pressure, respectively; $\Delta P=\mathrm{SBP}-\mathrm{DBP}, \rho$ the blood mass density, PWV either the left or right heart-to-ankle 
pulse wave velocity, and $a$ and $b$ proprietary scale conversion constants. PWV (heartankle) is calculated as $\frac{L}{\mathrm{tb}_{\mathrm{R}}+\mathrm{tba}_{\mathrm{L} / \mathrm{R}}}$, where $L$ is length from the aortic valve to the ankle, $\mathrm{tb}_{\mathrm{R}}$ is the time between aortic valve's closing sound and the notch of right brachial pulse wave (approximately equal to the time between aortic valve's opening sound and the rise of brachial pulse wave), and $\mathrm{tba}_{\mathrm{L} / \mathrm{R}}$ is the time between the foot of the right brachial pulse wave and the foot of either the left $\left(\mathrm{tba}_{\mathrm{L}}\right)$ or right $\left(\mathrm{tba}_{\mathrm{R}}\right)$ ankle pulse wave, respectively yielding left and right CAVI. Note that $\mathrm{tb}_{\mathrm{R}}+\mathrm{tba}_{\mathrm{L} / \mathrm{R}}$ represents the transit time of the pulse wave from the aortic valve to the ankle (Shirai et al. 2006b; Spronck, Mestanik, et al. 2017).

Calculation of corrected cardio-ankle vascular index $C A V I_{0}$

Despite the claimed BP-independence of CAVI, given its own assumptions, CAVI is theoretically still slightly affected by BP during examination (Spronck, Avolio, et al.

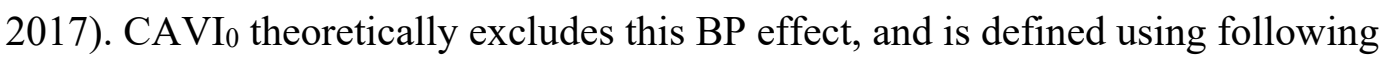
equations for calculation of left $\left(\mathrm{CAVI}_{0, \mathrm{~L}}\right)$ and right $\left(\mathrm{CAVI}_{0, \mathrm{R}}\right)$ corrected cardio-ankle vascular index:

$$
\begin{aligned}
& \mathrm{CAVI}_{0, \mathrm{~L}}=\frac{\left(\frac{L}{\mathrm{tb}_{\mathrm{R}}+\mathrm{tba}_{\mathrm{L}}}\right)^{2} \cdot 2 \rho}{\mathrm{DBP}}-\ln \left(\frac{\mathrm{DBP}}{P_{\text {ref }}}\right), \text { and } \\
& \mathrm{CAVI}_{0, \mathrm{R}}=\frac{\left(\frac{L}{\mathrm{tb}_{\mathrm{R}}+\mathrm{tba}_{\mathrm{R}}}\right)^{2} \cdot 2 \rho}{\mathrm{DBP}}-\ln \left(\frac{\mathrm{DBP}}{P_{\text {ref }}}\right) .
\end{aligned}
$$

$P_{\text {ref }}$ is an arbitrarily chosen fixed reference pressure (in the present study $P_{\text {ref }}=100$ mmHg) (Spronck, Mestanik, et al. 2017). 
Brachial and ankle systolic and diastolic BPs were measured and ankle-brachial index (ABI) was calculated as a ratio of the left or right ankle systolic BP to average value of the left and right brachial systolic BPs (if an interarm systolic BP gradient was less than $10 \mathrm{mmHg}$ ) or to higher value of the brachial systolic BPs (if an interarm systolic BP gradient was $10 \mathrm{mmHg}$ or more).

\section{Statistical analyses}

Data were analyzed using statistical software package SAS (SAS Institute, Cary, NC, USA). Data were tested for normality of distribution using the Shapiro-Wilk test and for homogeneity of variance using Levene's test. The comparison of differences between age groups $(7-10,11-14$, and 15-19 years) was performed using analysis of variance (ANOVA) and post hoc Fisher's Least-Significant-Difference test for data with normal distribution and equal variance or using Kruskal-Wallis test with post hoc Dwass, Steel, Critchlow-Fligner multiple pairwise comparison for between-groups comparison of parameters with non-normal distribution or unequal variance. Sex differences were analyzed using unpaired two sample Student t-test for data with normal distribution and using Mann-Whitney U test for variables with non-normal distribution.

Data were additionally analyzed using linear regression modelling with CAVI or CAVI, as dependent variables. Ten candidate predictors were measured in this study (age, sex, height, weight, WC, BSA, BMI, adult BMI, BRI, and ABSI). Age and sex were forced into all regression models. Models in/excluding any combination of the 
other 8 candidate predictors were created $\left(2^{8}=256\right.$ models $)$, and for each model the Akaike Information Criterion (AIC) was calculated. The model with the lowest AIC for which the variance inflation factor (VIF) of all parameters was $<10$, was subsequently chosen as most appropriate. Regression analyses were followed by 1) a check for the presence outliers using Cook's distance, and 2) a visual check for normality and homoscedasticity through residual plots. Independence (e.g., using a Durbin-Watson test) was not formally evaluated as all cases (subjects) were intrinsically independent.

For CAVI and $\mathrm{CAVI}_{0}$, the higher values from the left and the right side were used as the representative values in the results. $p<0.05$ was considered statistically significant. Data are expressed as mean \pm standard deviation or median (interquartile range). Combined scatter and percentile plots were generated using the statistical package $\mathrm{R}$ (version 3.3.2) (R Foundation for Statistical Computing; Vienna; Austria 2015) and the quantregGrowth (version 0.3-2) package that implements quantile regression (Muggeo et al. 2013). 


\section{RESULTS}

Sex- and age-specific distributions of CAVI and CAVI 0 are presented in Figure 1; sexspecific percentiles of CAVI and $\mathrm{CAVI}_{0}$ in the age groups of 7-10, 11-14, and 15-19 years of age are presented in Table 1. The anthropometric characteristics of the sex and age groups are summarized in Table 2 .

\section{Arterial stiffness parameters CAVI and CAVIo}

\section{Comparisons of age and sex groups}

The effect of age group (7-10,11-14, and 15-19 years of age) on arterial stiffness parameters CAVI and CAVI 0 was significant for both boys $\left(F_{[2]}=19.17, p<0.001\right.$; $F_{[2]}=24.62, p<0.001$; respectively $)$ and girls $\left(\chi^{2}{ }_{[2]}=54.17, p<0.001 ; \chi^{2}{ }_{[2]}=42.34, p<0.001\right.$; respectively). Post hoc analysis revealed a progressive increase in $\mathrm{CAVI}_{0}$ from $7-10$ to 15-19 years of age for both boys and girls with significantly higher CAVI $\mathrm{I}_{0}$ in the groups aged 11-14 compared to $7-10$ years $(p<0.001, p<0.05$, respectively) and in the groups aged 15-19 compared to 7-10 and 11-14 years ( $p<0.001$ for all comparisons). CAVI was significantly increased in both boys and girls aged 15-19 compared to 7-10 ( $p<0.001$ for both) and 11-14 years ( $p<0.01, p<0.001$, respectively). CAVI was significantly higher in boys aged $11-14$ compared to $7-10$ years $(p<0.01)$ but not in girls aged $11-14$ compared to $7-10$ years $(p=0.096$; Table 3 ).

Among the groups of children aged 7-10, 11-14, and 15-19 years, the boys aged 15-19 years were characterized by significantly lower CAVI compared to girls $(p<0.05)$ with 
no significant difference in $\mathrm{CAVI}_{0}(p=0.759$; Table 3$)$. No significant sex differences were found in parameters of arterial stiffness in groups aged 7-10 and 11-14 years.

Regression analysis

Based on the AIC, we determined the strongest predictors for CAVI and $\mathrm{CAVI}_{0}$ in the total group of 500 participants. The statistical models including these parameters and additionally including age and sex are shown in Table 4.

CAVI was strongly determined by age, weight, and BRI. Note that sex did not (linearly) influence CAVI $(p=0.395)$. CAVI 0 was strongly determined by age, BRI, and BMI. Again, sex did not (linearly) influence CAVIo $(p=0.441)$.

None of the presented regression models suffered from influential outliers (largest Cook's distance of 0.034 ), non-normality, or heteroscedasticity.

\section{Cardiovascular parameters}

Comparisons of age and sex groups

Heart rate, diastolic BP, pulse pressure, and $\mathrm{ABI}$ differed significantly among age groups in both boys $\left(\chi^{2}{ }_{[2]}=53.10, p<0.001 ; F_{[2]}=12.74, p<0.001 ; \chi^{2}{ }_{[2]}=34.02, p<0.001\right.$; $F_{[2]}=36.02, p<0.001$; respectively $)$ and girls $\left(\chi^{2}{ }_{[2]}=49.53, p<0.001 ; F_{[2]}=3.31, p<0.05\right.$; $\chi^{2}{ }_{[2]}=13.88, p<0.001 ; F_{[2]}=72.73, p<0.001$; respectively). The effect of age group on systolic BP was significant only in boys $\left(F_{[2]}=30.14, p<0.001\right)$ with no significant effect 
in girls $\left(F_{[2]}=1.12, p=0.328\right)$. Results of the post hoc comparisons are summarized in Table 3.

Among the age groups, heart rate was significantly higher in girls compared to boys in the groups of 11-14 and 15-19 years of age ( $p<0.001$ for both) with a tendency toward significantly higher heart rate in girls aged $7-10$ years $(p=0.071)$. Systolic BP was significantly higher in boys compared to girls aged $15-19$ years $(p<0.001)$ with no significant sex differences in the groups of $7-10$ and $11-14$ years of age $(p=0.529$, $p=0.465$, respectively). Pulse pressure was significantly higher in boys compared to girls in the groups of $11-14$ and 15-19 years of age $(p<0.05, p<0.001$, respectively) with no significant sex difference in subjects aged $7-10$ years $(p=0.821)$. ABI was significantly higher in boys compared to girls in the groups of 7-10 and 11-14 years of age $(p<0.01, p<0.001$, respectively) with no significant sex difference in subjects aged $15-19$ years $(p=0.610)$. No significant sex differences were found for diastolic BP. The sex comparisons in age groups are summarized in Table 3. 


\section{DISCUSSION}

The present study provides pediatric age- and sex-specific reference values for arterial stiffness parameters CAVI and CAVI 0 . We found that $\mathrm{CAVI}_{0}$ showed, to some extent, more robust assessment of the age-linked differences in arterial stiffness in healthy children than CAVI. Regarding the sex differences, CAVIo was not significantly different between boys and girls in all the three groups of 7-10, 11-14, and 15-19 years of age. In contrast, among adolescents aged 15-19 years, boys had lower CAVI which was associated with higher systolic and pulse pressure compared to girls, a finding that could be explained from CAVI's slight theoretical blood pressure dependence. The novel body index BRI was a strong anthropometric predictor for both CAVI and CAVIo.

The concept of arterial stiffness refers to mechanical properties of the load-bearing structures of arterial wall, such as collagen and elastin fibers, as well as to the effects of functional components including changes of smooth muscle tone related to alphaadrenergic innervation, endothelial function and multiple humoral factors (A. Avolio 2013; Townsend et al. 2015). The stiffness of the arterial wall is an essential determinant of the vascular impedance (the relationship between changes in BP and blood flow) which determines the buffer and conduit functions of arteries as well as ventricular-vascular coupling considered as a key pathophysiological mechanism of several cardiovascular diseases (Townsend et al. 2015). Therefore, early assessment of the loss of arterial wall elasticity provides an important non-invasive marker of subclinical vascular damage. However, the clinical application of distinct arterial stiffness parameters depends on a detailed knowledge of their physiological 
developmental characteristics, particularly in children and adolescents characterized by vulnerable age-related developmental processes.

Arterial structure begins to resemble the adult form between the 2 and 8 years of age (Senzaki et al. 2002; Voges et al. 2012). During childhood, arteries undergo significant growth-related changes, e.g., thickening of the muscular medial layer related to progressively increasing BP, reduction of vascular compliance and distensibility associated with early medial restructuring and increased deposition of collagen (A. P. Avolio et al. 1983; Sarkola et al. 2012; Senzaki et al. 2002). The stiffness of the arterial wall is a result of (the balance between) these mechanisms. Previous studies in children and adolescents reported an age-dependent increase of arterial stiffness assessed using PWV (A. P. Avolio et al. 1983; Fischer et al. 2012; Laurent et al. 2006). However, PWV increases with higher BP during examination, which may lead to potentially inaccurate results (Spronck et al. 2015). Interestingly, CAVI, which had been previously claimed as a BP-independent index of arterial stiffness, is theoretically also affected by acute changes of BP (Spronck, Avolio, et al. 2017). In the present study, contrary to CAVI, CAVI was not significantly different between girls aged 7-10 and 11-14 years, who were characterized by similar systolic and diastolic BP. Moreover, boys aged 1519 years showed significantly lower CAVI, which was associated with higher systolic BP compared to girls. These findings are in line with recent analyses showing that CAVI decreases with greater actual systolic BP and increases with greater diastolic BP (Spronck, Avolio, et al. 2017). In contrast to CAVI, CAVI0 showed a continuous progressive increase in both sexes. 
The finding of elevated systolic BP in adolescent boys may be related to the previously described effects of a large increase in body height in youth, when the large vessels are still very elastic (O’Rourke, Vlachopoulos, and Graham 2000). In adolescents and young adults, elevated brachial systolic BP may result from unusually high amplification of brachial pressure wave due to low aortic PWV and a relatively late return of the reflected wave from distant peripheral arteries (O'Rourke and Adji 2017; O'Rourke, Vlachopoulos, and Graham 2000). This mechanism is apparent mostly in young, tall men who may be frequently diagnosed with "spurious", peripheral systolic hypertension while their central systolic BP is normal (O'Rourke and Adji 2013, 2017; O'Rourke, Vlachopoulos, and Graham 2000). This effect may be present also in our study, where the boys aged 15-19 years were significantly taller and had significantly higher systolic BP than the respective group of girls. For a correct evaluation of BP in youth and its application in prediction of cardiovascular events, it may be of particular importance to consider that the predictive effects of BP on a PWV increase differ between adolescents and adults. Specifically, in older adults, systolic BP was considered to be a better predictor of cardiovascular risk compared to diastolic BP, whereas in adolescents diastolic BP was a better predictor of increased aortic stiffening later in life (Aatola et al. 2017; O’Rourke, Vlachopoulos, and Graham 2000; Rutan et al. 1988; SHEP Cooperative Research Group 1991). Moreover, independent of childhood BP status, adults with high BP have a greater risk of high PWV compared to persistently normotensive individuals; however, in those with a former (pediatric) hypertension, the resolution of elevated BP from childhood to adulthood resulted in reduction of this risk (Aatola et al. 2017). Therefore, evaluation of BP-independent indices of arterial stiffness in a pediatric population may offer clinically important information about 
cardiovascular risk with a potentially superior predictive value compared to a sole evaluation of BP or application of conventional methods for PWV assessment.

With respect to sex differences in arterial stiffness during childhood, previous studies showed conflicting results. Voges et al. found no sex differences in arterial stiffness assessed using aortic PWV and distensibility (Voges et al. 2012). On the contrary, Ahimastos et al. (Ahimastos et al. 2003) found that carotid-femoral PWV in children aged $10.3 \pm 0.1$ years (mean \pm SD) was higher in girls than boys, but found no significant difference between adolescent girls and boys. Furthermore, peripheral PWV was higher in younger girls but lower in adolescent girls compared to the respective groups of boys. It is important to note that these sex differences in PWV were associated with congruent differences in BP which could have contributed to these findings (Ahimastos et al. 2003). Similarly, in the present study, it seems that sex differences in CAVI in adolescents aged 15-19 years are more likely related to the effect of difference in systolic BP than to a difference in developmental processes. Moreover, CAVI and $\mathrm{CAVI}_{0}$ were not significantly influenced by sex in the regression analysis.

Anthropometrically, the novel parameter BRI was shown to be among the best predictors of CAVI and CAVI 0 . The negative relationship between BRI and $\mathrm{CAVI} / \mathrm{CAVI}_{0}$ is in accordance with previously found inverse relationship between $\mathrm{CAVI} / \mathrm{CAVI}_{0}$ and overweight evaluated using BMI in adolescent age (Mestanik et al. 2017; Philip et al. 2015).

The present study's cross-sectional nature limits its use in assessing the individual evolution of the parameters of arterial stiffness over time. Further longitudinal studies are needed to assess the relationship between increased values of CAVI and $\mathrm{CAVI}_{0}$ in 
childhood and the risk of cardiovascular events in adulthood and to subsequently define specific CAVI or CAVIo cut-off points for management of preventive and therapeutic interventions. Furthermore, the studied cohort included only Caucasian children and adolescents from the Central European region what may limit the ability to extrapolate the reference values to alternative populations. 


\section{Conclusions}

In this paper, we present the first study providing age- and sex-specific reference values for the arterial stiffness parameters CAVI and $\mathrm{CAVI}_{0}$ in healthy children and adolescents aged 7 to 19 years. CAVIo showed, to some extent, more robust assessment of the differences in arterial stiffness between the age groups of boys and girls aged 710, 11-14, and 15-19 years compared to standard CAVI. In contrast to CAVI 0 , which showed no sex differences, CAVI was lower in boys aged 15-19 years compared to girls, which could be explained from the effect of higher systolic pressure. This finding supports the suggestion that $\mathrm{CAVI}_{0}$ could offer a more independent method for the assessment of arterial stiffness than CAVI. However, it should be noted that in general, CAVI and CAVIo show similar overall trends and differences between the two may emerge only under specific conditions. 
Conflicts of interest: None declared.

\section{ACKNOWLEDGEMENTS}

This work was supported by Slovak Scientific Grant Agency under grant VEGA

1/0044/18, Slovak Research and Development Agency under grant APVV-15-0075, and the project implementation „Biomedical Center Martin“ ITMS code: 26220220187, supported by the Operational Programme Research and Innovation funded by the ERDF 


\section{REFERENCES}

Aatola, Heikki et al. 2017. "Influence of Child and Adult Elevated Blood Pressure on Adult Arterial Stiffness: The Cardiovascular Risk in Young Finns Study.” Hypertension 70(3): 531-36.

Ahimastos, Anna A., Melissa Formosa, Anthony M. Dart, and Bronwyn A. Kingwell. 2003. "Gender Differences in Large Artery Stiffness Pre- and Post Puberty." The Journal of Clinical Endocrinology \& Metabolism 88(11): 5375-80. http://www.ncbi.nlm.nih.gov/pubmed/14602776 (July 13, 2017).

Avolio, A P et al. 1983. "Effects of Aging on Changing Arterial Compliance and Left Ventricular Load in a Northern Chinese Urban Community." Circulation 68(1): 50-58. http://www.ncbi.nlm.nih.gov/pubmed/6851054 (July 9, 2017).

Avolio, Alberto. 2013. “Arterial Stiffness.” Pulse 1(1): 14-28.

Cole, T. J., and T. Lobstein. 2012. "Extended International (IOTF) Body Mass Index Cut-Offs for Thinness, Overweight and Obesity.” Pediatric Obesity 7(4): 284-94.

Falkner, Bonita. 2008. "Children and Adolescents with Obesity-Associated High Blood Pressure." Journal of the American Society of Hypertension: JASH 2(4): 267-74. http://www.ncbi.nlm.nih.gov/pubmed/20409907 (May 23, 2018).

Fernhall, Bo, and Stamatis Agiovlasitis. 2008. "Arterial Function in Youth: Window into Cardiovascular Risk.” J Appl Physiol 105: 325-33.

Fischer, Dagmar-Christiane et al. 2012. "Pediatric Reference Values of Carotid-Femoral Pulse Wave Velocity Determined with an Oscillometric Device." Journal of 
Hypertension 30(11): 2159-67. http://www.ncbi.nlm.nih.gov/pubmed/22940681 (July 6, 2017).

Ghazi, Lama et al. 2017. “Assessment of Vascular Function in Low Socioeconomic Status Preschool Children: A Pilot Study." Journal of the American Society of Hypertension : JASH 11(2): 101-9.

http://www.ncbi.nlm.nih.gov/pubmed/28063813 (May 23, 2018).

Juhola, J et al. 2011. "Tracking of Serum Lipid Levels, Blood Pressure, and Body Mass Index from Childhood to Adulthood: The Cardiovascular Risk in Young Finns Study." The Journal of Pediatrics 159: 584-90.

Krakauer, Nir Y., and Jesse C. Krakauer. 2012. “A New Body Shape Index Predicts Mortality Hazard Independently of Body Mass Index" ed. Shengxu Li. PLoS ONE 7(7): e39504. http://www.ncbi.nlm.nih.gov/pubmed/22815707 (January 3, 2018).

Laurent, Stephane et al. 2006. "Expert Consensus Document on Arterial Stiffness:

Methodological Issues and Clinical Applications." European heart journal 27(21): 2588-2605. http://eurheartj.oxfordjournals.org/cgi/doi/10.1093/eurheartj/ehl254 (January 5, 2017).

Mestanik, Michal et al. 2016. "Arterial Stiffness Evaluated by Cardio-Ankle Vascular Index (CAVI) in Adolescent Hypertension." Canadian journal of physiology and pharmacology 94(1): 112-16. http://www.nrcresearchpress.com/doi/10.1139/cjpp2015-0147 (January 5, 2017).

— 2017. "Improved Assessment of Arterial Stiffness Using Corrected CardioAnkle Vascular Index (CAVI0) in Overweight Adolescents with White-Coat and 
Essential Hypertension." Scandinavian Journal of Clinical and Laboratory Investigation 77(8): 665-72.

Morita, Noriteru et al. 2016. "Inverse Relationship between Sleep Duration and CardioAnkle Vascular Index in Children." Journal of atherosclerosis and thrombosis. https://www.jstage.jst.go.jp/article/jat/advpub/0/advpub_36517/_article(July 5, 2017).

Mosteller, R D. 1987. “Simplified Calculation of Body-Surface Area.” New England Journal of Medicine 317(17): 1098-1098.

Muggeo, Vito M. R., Mariangela Sciandra, Agostino Tomasello, and Sebastiano Calvo. 2013. "Estimating Growth Charts via Nonparametric Quantile Regression: A Practical Framework with Application in Ecology." Environmental and Ecological Statistics 20(4): 519-31. http://link.springer.com/10.1007/s10651-012-0232-1 (January 3, 2018).

Nichols, Melanie, Nick Townsend, Peter Scarborough, and Mike Rayner. 2014. “Cardiovascular Disease in Europe 2014: Epidemiological Update.” European Heart Journal 35(42): 2950-59. http://www.ncbi.nlm.nih.gov/pubmed/25139896 (July 5, 2017).

O'Rourke, Michael F., and Audrey Adji. 2013. "Guidelines on Guidelines.” Journal of Hypertension 31(4): 649-54. http://www.ncbi.nlm.nih.gov/pubmed/23412425 (August 2, 2018).

—. 2017. "Managing Hypertension in Children and Adolescents." Journal of Hypertension 35(2): 417. http://insights.ovid.com/crossref?an=00004872- 
201702000-00030 (August 2, 2018).

O’Rourke, Michael F., Charalambos Vlachopoulos, and Robert M Graham. 2000. “Spurious Systolic Hypertension in Youth.” Vascular medicine (London, England) 5: $141-45$.

Okura, Takafumi et al. 2007. "Relationship between Cardio-Ankle Vascular Index (CAVI) and Carotid Atherosclerosis in Patients with Essential Hypertension." Hypertens Res 30(4): 335-40.

Park, Hyo Eun, Su-Yeon Choi, Min Kyung Kim, and Byung-Hee Oh. 2012. "CardioAnkle Vascular Index Reflects Coronary Atherosclerosis in Patients with Abnormal Glucose Metabolism: Assessment with 256 Slice Multi-Detector Computed Tomography." Journal of cardiology 60(5): 372-76. http://www.ncbi.nlm.nih.gov/pubmed/22890071 (August 15, 2014).

Philip, Ranjit et al. 2015. "Inverse Relationship between Cardio-Ankle Vascular Index and Body Mass Index in Healthy Children." The Journal of Pediatrics 167: 361365.e1.

R Foundation for Statistical Computing; Vienna; Austria. 2015. "R: A Language and Environment for Statistical Computing." https://www.r-project.org/.

Rutan, G H et al. 1988. "Mortality Associated with Diastolic Hypertension and Isolated Systolic Hypertension among Men Screened for the Multiple Risk Factor Intervention Trial.” Circulation 77(3): 504-14.

Sarkola, T. et al. 2012. "Evolution of the Arterial Structure and Function From Infancy 
to Adolescence Is Related to Anthropometric and Blood Pressure Changes." Arteriosclerosis, Thrombosis, and Vascular Biology 32(10): 2516-24.

http://www.ncbi.nlm.nih.gov/pubmed/22837471 (January 4, 2018).

Senzaki, Hideaki et al. 2002. "Age-Associated Changes in Arterial Elastic Properties in Children." European Journal of Pediatrics 161(10): 547-51.

SHEP Cooperative Research Group. 1991. "Prevention of Stroke by Antihypertensive Drug Treatment in Older Persons with Isolated Systolic Hypertension. Final Results of the Systolic Hypertension in the Elderly Program (SHEP).” JAMA 265(24): 3255-64.

Shirai, Kohji et al. 2011. "Cardio-Ankle Vascular Index (CAVI) as a Novel Indicator of Arterial Stiffness: Theory, Evidence and Perspectives.” Journal of atherosclerosis and thrombosis 18(11): 924-38. http://www.ncbi.nlm.nih.gov/pubmed/21628839.

Shirai, Kohji, Junji Utino, Kuniaki Otsuka, and Masanobu Takata. 2006a. “A Novel Blood Pressure-Independent Arterial Wall Stiffness Parameter; Cardio-Ankle Vascular Index (CAVI)." Journal of atherosclerosis and thrombosis 13(2): 101-7. http://www.ncbi.nlm.nih.gov/pubmed/16733298.

2006b. “A Novel Blood Pressure-Independent Arterial Wall Stiffness Parameter; Cardio-Ankle Vascular Index (CAVI)." Journal of atherosclerosis and thrombosis 13(2): 101-7.

Spronck, Bart et al. 2015. "Pressure-Dependence of Arterial Stiffness : Potential Clinical Implications.” Journal of Hypertension 33(2): 330-38. 
Spronck, Bart, Alberto P. Avolio, et al. 2017. “Arterial Stiffness Index Beta and CardioAnkle Vascular Index Inherently Depend on Blood Pressure but Can Be Readily Corrected.” Journal of Hypertension 35(1): 98-104.

Spronck, Bart, M. Mestanik, et al. 2017. "Direct Means of Obtaining CAVI0 - A Corrected Cardio-Ankle Vascular Stiffness Index (CAVI) - From Conventional CAVI Measurements or Their Underlying Variables.” Physiological Measurement 38(10): N128-37.

Thomas, Diana M et al. 2013. "Relationships between Body Roundness with Body Fat and Visceral Adipose Tissue Emerging from a New Geometrical Model.” Obesity 21(11): 2264-71.

Townsend, Raymond R et al. 2015. "Recommendations for Improving and Standardizing Vascular Research on Arterial Stiffness: A Scientific Statement From the American Heart Association.” Hypertension 66(3): 698-722.

Voges, Inga et al. 2012. "Normal Values of Aortic Dimensions, Distensibility, and Pulse Wave Velocity in Children and Young Adults: A Cross-Sectional Study." Journal of Cardiovascular Magnetic Resonance 14(1): 77.

http://www.ncbi.nlm.nih.gov/pubmed/23151055 (July 6, 2017).

Wang, Hongyu et al. 2013. “Arterial Stiffness Evaluation by Cardio-Ankle Vascular Index in Hypertension and Diabetes Mellitus Subjects.” Journal of the American Society of Hypertension: JASH 7(6): 426-31.

http://www.ncbi.nlm.nih.gov/pubmed/23871571 (May 23, 2018).

Wohlfahrt, Peter et al. 2017. "Reference Values of Cardio-Ankle Vascular Index in a 
Random Sample of a White Population.” Journal of Hypertension: 1.

http://www.ncbi.nlm.nih.gov/pubmed/28594708 (July 13, 2017). 


\section{FIGURE CAPTIONS}

Figure 1. Combined scatter and percentile plots of arterial stiffness parameters cardioankle vascular index (CAVI) and blood pressure-corrected index CAVI ${ }_{0}$. 

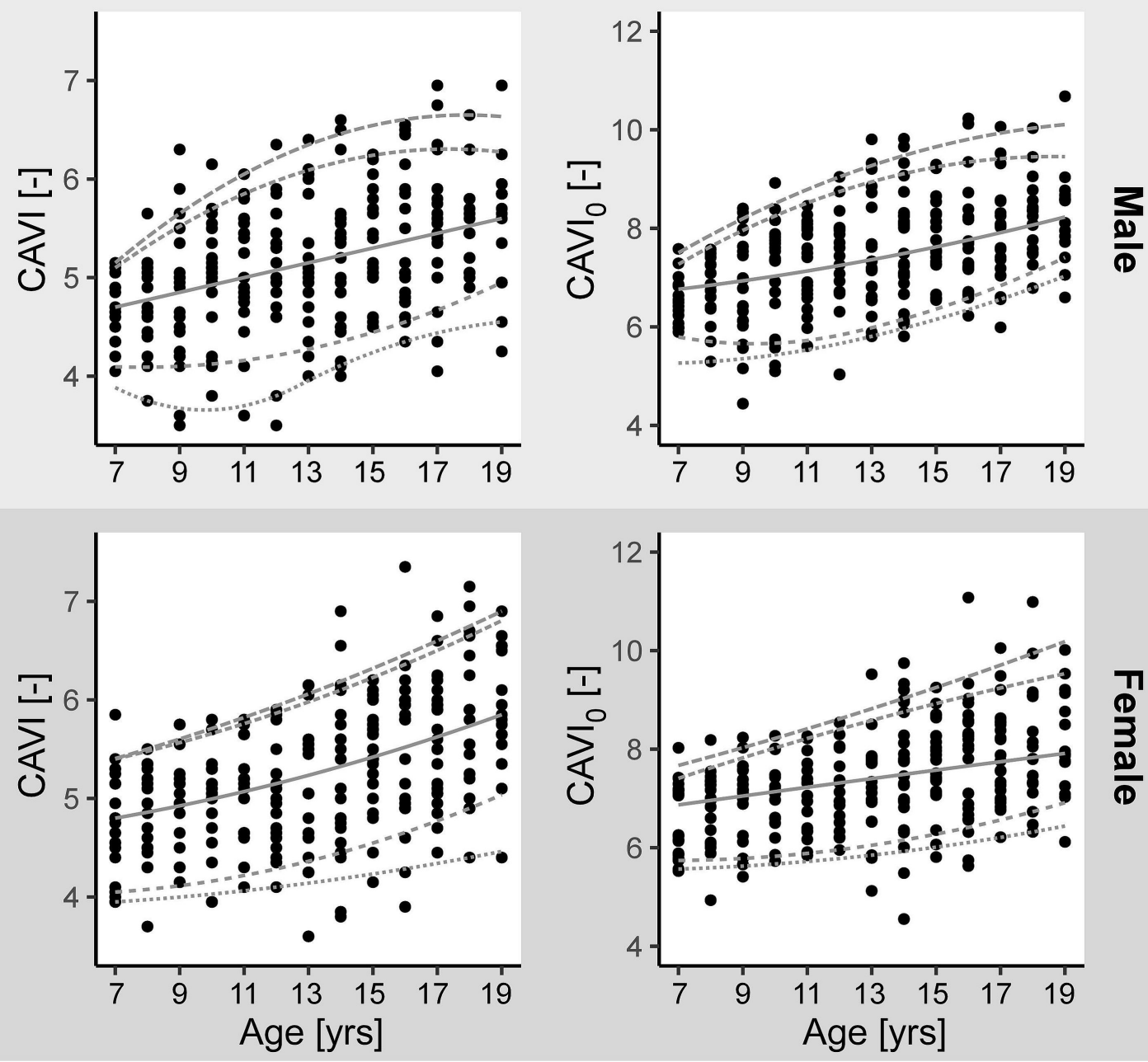

Legend: percentiles:

5

$10-50$

90 